NBER WORKING PAPER SERIES

\title{
THE CROSS-SECTION OF HOUSEHOLD PREFERENCES
}

\author{
Laurent E. Calvet \\ John Y. Campbell \\ Francisco Gomes \\ Paolo Sodini \\ Working Paper 28788 \\ http://www.nber.org/papers/w28788 \\ NATIONAL BUREAU OF ECONOMIC RESEARCH \\ 1050 Massachusetts Avenue \\ Cambridge, MA 02138 \\ May 2021, Revised November 2022
}

We acknowledge helpful comments on earlier versions of this paper from Stijn van Nieuwerburgh, Jessica Wachter, Stanley Zin, and seminar participants at Arizona State University, EDHEC Business School, ENSAE-CREST, Harvard University, Imperial College London, Stanford University, the University of Michigan, the Vienna Graduate School of Finance, the 2017 American Economic Association meeting, the UCLA Anderson Fink Center Conference on Financial Markets, the 2019 FMND Workshop, the 2019 NBER Asset Pricing Summer Institute, the 2021 London Seminar on Micro and Macro Implications of Household Behaviour and Financial Decision-Making, and the 2021 NBER Big Data Conference. We thank the Sloan Foundation for financial support to John Campbell, and Azar Aliyev, Nikolay Antonov, Huseyin Aytug, Yapei Zhang and Yuhuang Sun for able and dedicated research assistance. The views expressed herein are those of the authors and do not necessarily reflect the views of the National Bureau of Economic Research.

At least one co-author has disclosed additional relationships of potential relevance for this research. Further information is available online at http://www.nber.org/papers/w28788.ack

NBER working papers are circulated for discussion and comment purposes. They have not been peer-reviewed or been subject to the review by the NBER Board of Directors that accompanies official NBER publications.

(C) 2021 by Laurent E. Calvet, John Y. Campbell, Francisco Gomes, and Paolo Sodini. All rights reserved. Short sections of text, not to exceed two paragraphs, may be quoted without explicit permission provided that full credit, including (C) notice, is given to the source. 
The Cross-Section of Household Preferences

Laurent E. Calvet, John Y. Campbell, Francisco Gomes, and Paolo Sodini

NBER Working Paper No. 28788

May 2021, Revised November 2022

JEL No. E21,G51

\section{ABSTRACT}

This paper estimates the cross-sectional distribution of Epstein-Zin preferences using the wealth and risky portfolio shares of a large panel of Swedish households. We find heterogeneous risk aversion (a standard deviation of 1.06 with a mean/median of 7.57/7.50), time preference rate (standard deviation $6.96 \%$ with a mean/median of 5.21/3.15\%) and elasticity of intertemporal substitution (standard deviation 0.90 with a mean/median of $0.96 / 0.50$ ). Risk aversion and the EIS are only very weakly negatively correlated. We estimate lower risk aversion for households with riskier labor income, and a higher TPR and lower EIS for households who enter our sample with low wealth.

Laurent E. Calvet

Department of Finance

EDHEC

16 rue du Quatre-Septembre

75002 Paris

France

laurent.calvet@edhec.edu

John Y. Campbell

Morton L. and Carole S.

Olshan Professor of Economics

Department of Economics

Harvard University

Littauer Center 213

Cambridge, MA 02138

and NBER

john_campbell@harvard.edu
Francisco Gomes

Finance Department

London Business School

Sussex Place

London NW1 4SA

UK

fgomes@london.edu

Paolo Sodini

Department of Finance

Stockholm School of Economics

Sveavägen 65

Box 6501

SE-113 83 Stockholm

Sweden

Paolo.Sodini@hhs.se

A data appendix is available at http://www.nber.org/data-appendix/w28788 
When households make financial decisions, are their preferences toward time and risk substantially similar, or do they vary cross-sectionally? And if preferences are heterogeneous, how do preference parameters covary in the cross-section with one another and with household attributes such as education and sector of employment? This paper answers these questions using a life-cycle model of saving and portfolio choice fit to high-quality household-level administrative data from Sweden.

Financial theory distinguishes at least three parameters that govern financial decisions: the time preference rate (TPR), the coefficient of relative risk aversion (RRA), and the elasticity of intertemporal substitution (EIS). The canonical model of Epstein and Zin (1989) makes all three parameters constant and invariant to wealth for a given household, while breaking the reciprocal relation between the RRA and the EIS implied by the older power utility model.

We structurally estimate these three preference parameters in the cross-section of Swedish households by embedding Epstein-Zin preferences in a life-cycle model of consumption and portfolio choice in the presence of uninsurable labor income risk and borrowing constraints. Our baseline implementation assumes that all agents have common beliefs about income processes and financial returns, but we also consider a simple form of heterogeneity in beliefs about risky asset returns.

To mitigate the effects of idiosyncratic events not captured by the model, we carry out our estimation on groups of households who share certain observable features, making use of asymptotic properties of our estimation procedure as the size of each group increases. We first group households by their education level, the level of income risk in their sector of employment, and birth cohort. To capture heterogeneity in preferences that is unrelated to these characteristics we further divide households by their initial wealth in relation to income and by their initial 
risky portfolio share. This process gives us a sample of 4276 composite households that have data available in each year of our sample from 1999 to 2007.

We allow age-income profiles to vary with education, and the determinants of income risk to vary with both education and the household's sector of employment. These assumptions are standard in the life-cycle literature (Carroll and Samwick 1997, Cocco, Gomes, and Maenhout 2005). These life-cycle models more readily match portfolio allocations and wealth accumulation at mid-life than at younger ages or after retirement. Therefore we estimate the preference parameters by matching the time series of wealth and portfolio choice between ages 40 and 60, taking as given wealth-income at the start of each year as well as realized group-level income shocks and risky asset returns during the year.

Our measure of wealth includes liquid financial wealth, real estate, definedcontribution retirement assets, and household entitlements to defined-benefit pension income. Our imputation of defined-contribution retirement wealth is an empirical contribution that extends previous research on Swedish administrative data. We confine attention to households who hold some risky financial assets outside retirement accounts, for comparability with previous work and in order to avoid the need to estimate determinants of non-participation in risky financial markets. To reduce the dimensionality of the model, we map both real estate and risky financial asset holdings into implied holdings of a single composite risky asset.

We address the challenge of identifying all three Epstein-Zin preference parameters. In principle, these parameters play different roles with the TPR affecting only the overall slope of the household's planned consumption path, risk aversion governing the willingness to hold risky financial assets and the strength of the precautionary savings motive, and the EIS affecting both the overall slope of the planned 
consumption path and the responsiveness of this slope to changes in background risks and investment opportunities. We observe portfolio choice directly, and the slope of the planned consumption path indirectly through its relation with saving and hence wealth accumulation.

Identifying the EIS separately from the TPR requires time-variation in background risks or investment opportunities (Kocherlakota 1990, Svensson 1989). Our model is fully identified because it generates endogenous variation in household risk exposures. Households in the model have a target level of financial wealth that serves to smooth income variation and finance retirement. Households below the target save more aggressively if they have a higher EIS. Relatedly, households with high financial wealth relative to human capital invest more conservatively, which reduces the expected return on their financial wealth. In addition as households age their mortality rates increase, and this alters the effective rate of time discounting. For all these reasons we can identify the EIS from wealth accumulation profiles. This identification strategy is a methodological contribution of our paper.

Our main empirical findings are as follows. First, we find considerable heterogeneity in wealth accumulation and portfolio composition across the Swedish population. Average wealth-income ratios increase strongly with the riskiness of income and the level of education while average risky shares do not, but both variables have substantial heterogeneity unrelated to these variables.

Second, we document patterns in wealth and portfolio composition that are broadly consistent with financial theory. As households age, they accumulate wealth and reduce their risky portfolio share. The risky portfolio share also declines with the wealth-income ratio conditional on age. Both patterns are predicted by a life-cycle model in which human capital is safer than risky financial capital. 
Third, we estimate heterogeneity in all three preference parameters. Relative to its mean, the least heterogeneity is in risk aversion, which has a cross-sectional standard deviation of 1.06 around a mean of 7.57. Our other two preference parameters are highly dispersed and right-skewed. The mean TPR is $5.21 \%$, well above the median value of $3.15 \%$, and the standard deviation is $6.96 \%$. The mean EIS is 0.96 , well above the median value of 0.50 , and the standard deviation is 0.90 .

Fourth, our preference parameter estimates are only weakly cross-sectionally correlated. The correlation between risk aversion and the EIS is very weakly negative $(-0.114)$, in contrast with the perfect negative correlation between log risk aversion and the log EIS that we would find if all households had power utility with heterogeneous coefficients. The TPR is weakly positively correlated with risk aversion (0.191) and weakly negatively correlated with the EIS (-0.217), implying a tendency for impatient people to be both cautious and unwilling to substitute intertemporally. The weak correlations across preference parameters imply that Swedish household behavior is heterogeneous in multiple dimensions, not just one. A single source of heterogeneity omitted from our model cannot explain this pattern.

Fifth, we document notable correlations between our parameter estimates, the moments we use for estimation, and exogenous characteristics of households. Risk aversion is lower for households working in risky sectors. This pattern is consistent with the hypothesis that risk-tolerant households choose to acquire education and select risky occupations, but it could also result from the failure to understand the portfolio implications of their income risk and wealth accumulation. In addition, the TPR is negatively correlated with the initial wealth-income ratio of each household group, and positively correlated with the average growth rate of the wealth-income ratio. The symptom of a high TPR in our data is a tendency to accumulate retirement savings later in life. The equivalent correlations for the EIS have the opposite signs, 
suggesting that households with a high EIS save early in life to reach a target wealth-income ratio, while households with a low EIS save more gradually.

Sixth, when we allow for a simple form of heterogeneity in beliefs about the Sharpe ratio on risky assets, we find that belief heterogeneity has little effect on the fit of our model and does not reduce the cross-sectional dispersion of estimated preference parameters. The dispersion in estimated risk aversion actually increases, because our model uses heterogeneous beliefs to fit savings behavior and adjusts risk aversion to avoid counterfactual implications for risky portfolio shares. Moreover, the fit of the model deteriorates drastically when we allow for heterogeneity in beliefs about the Sharpe ratio but restrict preferences to be homogeneous across households, which confirms the importance of the preference heterogeneity we estimate.

Our paper is related to a large literature on portfolio choice over the life cycle 1 and a series of papers using the Swedish administrative data. ${ }^{2}$ A smaller literature on heterogeneity in portfolio choice has recently tried to relate observed household behavior to underlying heterogeneity in preferences and beliefs (Giglio, Maggiori, Stroebel, and Utkus 2021, Meeuwis, Parker, Schoar, and Simester 2021). Relative to this literature, we observe more households over a longer period of time and have more complete data on wealth and portfolio allocation, but we lack data on potentially heterogeneous beliefs.

The organization of the paper is as follows. Section 1 explains how we measure household wealth and reports summary statistics. Section 2 presents the life-cycle model. Section 3 develops our estimation methodology. Section 4 reports empirical

\footnotetext{
${ }^{1}$ See for instance Campbell and Viceira (2002), Cocco, Gomes, and Maenhout (2005), and Fagereng, Gottlieb, and Guiso (2017).

${ }^{2}$ See, for example, Calvet, Campbell, and Sodini (2007, 2009), Calvet and Sodini (2014), Betermier, Calvet, and Sodini (2017), and Bach, Calvet, and Sodini (2020).
} 
results. Section 5 concludes. An online appendix provides additional results and details about our empirical analysis and estimation technique.

\section{Measuring Household Wealth and Asset Allocation}

Our empirical analysis is based on the Swedish Wealth and Income Registry. This high-quality administrative panel provides the income, wealth, and debt of every Swedish resident. Income data are available at the individual level from 1983 and can be aggregated to the household level from 1991. Wealth data are available from 1999 through 2007. The wealth data include bank account balances, holdings of financial assets, and real estate properties measured at the level of each security or property. We augment the dataset by imputing defined contribution (DC) retirement wealth and entitlements to defined benefit (DB) pension income using income data and the administrative rules governing Swedish pensions.

\subsection{The Household Balance Sheet}

We measure four components of the household balance sheet: liquid financial wealth, real estate wealth, DC retirement savings, and debt. We define the total net wealth of household $h$ at time $t, W_{h, t}$, as

$$
W_{h, t}=L W_{h, t}+R E_{h, t}+D C_{h, t}-D_{h, t},
$$


where $L W_{h, t}$ is liquid financial wealth, $R E_{h, t}$ is real estate wealth, $D C_{h, t}$ is DC retirement wealth, and $D_{h, t}$ is debt. Non-cash net wealth is

$$
N C W_{h, t}=L W_{h, t}^{S}+R E_{h, t}+D C_{h, t}^{S}-D_{h, t},
$$

where $L W_{h, t}^{S}$ and $D C_{h, t}^{S}$ are the risky components of liquid financial wealth and DC wealth, respectively.

Liquid financial wealth is the value of the household's bank accounts and holdings of Swedish money market funds, mutual funds, stocks, capital insurance products, derivatives and fixed income securities. Mutual funds include balanced funds and bond funds, as well as equity funds. We subdivide liquid financial wealth into cash, defined as the sum of bank balances and money market funds, and risky assets.

Real estate consists of primary and secondary residences, rental, commercial and industrial properties, agricultural properties and forestry. The pricing of real estate properties is based on market transactions and tax values adjusted by a multiplier, as in Bach, Calvet, and Sodini (2020).

Debt is the sum of all liabilities of the household, including mortgages and other personal liabilities held outside private businesses. Since Swedish household debt is normally floating-rate, we treat debt as equivalent to a negative cash position but paying a borrowing rate that is higher than the safe lending rate.

We impute DC retirement wealth by reconstructing the contribution rules of several types of Swedish DC pensions. We accumulate these contributions since 1991, with appropriate assumptions about asset allocation and the initial level of DC pension wealth in 1991. We describe this procedure in detail in the appendix. DC retirement wealth accumulates untaxed but is taxed upon withdrawal. To convert 
pre-tax retirement wealth into after-tax units that are comparable to liquid financial wealth, we assume an average tax rate $\tau$ on withdrawals (estimated at $32 \%$ which is the average tax rate on nonfinancial income paid by households with retired heads over 65 years old) and multiply pre-tax wealth by $(1-\tau)$. In the remainder of the paper, we always state retirement wealth in after-tax units.

As described here, the household balance sheet excludes durables and private businesses, whose values are particularly difficult to measure. Private businesses are an important component of wealth for the wealthiest households in Sweden, but unimportant for most Swedish households (Bach, Calvet, and Sodini 2020).

\subsection{Household Asset Allocation}

Our objective is to match the rich dataset of household income and asset holdings to the predictions of a life-cycle model. To accomplish this, we need to map the complex data into a structure that can be related to a life-cycle model with one riskless and one risky asset. This mapping proceeds in three stages.

At the first stage, we map all individual assets to equivalent holdings of diversified stocks, real estate, or cash. We treat liquid holdings of individual stocks, equity mutual funds, and hedge funds as diversified holdings of the MSCI world equity index. 3 We treat liquid holdings of balanced funds and bond funds as portfolios of cash and stocks, where cash pays the Swedish Treasury bill rate and where the share in stocks is given by the beta of each fund with the world index..$^{4}$ We treat all real

\footnotetext{
${ }^{3}$ This reflects the global exposure of Swedish equity portfolios documented by Calvet, Campbell, and Sodini (2007). It abstracts from underdiversification which is documented in the same paper. The impact of underdiversification in liquid wealth is reduced when one takes account of diversified DC retirement wealth as we do in this paper.

${ }^{4}$ We cap the estimated fund beta at 1 , and use the cross-sectional average fund beta for funds with
} 
estate holdings as positions in a diversified index of Swedish residential real estate, the FASTPI index. We assume that DC retirement wealth is invested in cash and the MSCI equity world index, as section 1.2 of the online appendix explains. 5

For each household $h$ at time $t$, this mapping gives us the implied weights of liquid stocks, $\omega_{h, t}^{S}$, real estate, $\omega_{h, t}^{R E}$, DC stocks, $\omega_{h, t}^{D C S}$, and debt, $\omega_{h, t}^{D}$, in the household's non-cash net wealth. The excess return on non-cash net wealth is then:

$$
R_{N C W, h, t+1}^{e}=\omega_{h, t}^{S} R_{S, t+1}^{e}+\omega_{h, t}^{R E} R_{R E, t+1}^{e}+\omega_{h, t}^{D C S} R_{D C S, t+1}^{e}-\omega_{h, t}^{D} R_{D, t+1}^{e} .
$$

where $R_{S, t+1}^{e}, R_{R E, t+1}^{e}$, and $R_{D C S, t+1}^{e}$ denote the excess return over cash on risky liquid wealth, real estate, and risky DC wealth, respectively, and $R_{D, t+1}^{e}$ is the household borrowing rate over cash.

The second stage of our analysis is to calculate the variance of $R_{N C W, h, t+1}^{e}$. Since the borrowing rate is deterministic, we only need to consider the vector $\omega_{h, t}=\left(\omega_{h, t}^{S}, \omega_{h, t}^{R E}, \omega_{h, t}^{D C S}\right)^{\prime}$ and the variance-covariance matrix $\Sigma$ of $R_{t+1}^{e}=$ $\left(R_{S, t+1}^{e}, R_{R E, t+1}^{e}, R_{D C S, t+1}^{e}\right)^{\prime}$. The variance of $R_{N C W, h, t+1}^{e}$ is then $\sigma^{2}\left(R_{N C W, h, t+1}^{e}\right)=$ $\omega_{h, t}^{\prime} \Sigma \omega_{h, t}$. To estimate $\Sigma$, we assume that cash earns the Swedish one-month riskfree rate net of taxes, that liquid equity earns the MSCI world index return net of a $30 \%$ long-term capital income tax rate (Du Rietz et al. 2015), that real estate earns the FASTPI index return net of a $22 \%$ real estate capital gain tax rate, and that stocks held in DC plans earn the pre-tax MSCI world index return before the adjustment of their value to an after-tax basis. Using data from 1984-2007, we estimate the post-tax excess return volatility for stocks at $13.3 \%$ and for real estate at 5.5\%, with a correlation of 0.27 . The pre-tax excess stock return volatility is $19 \%$.

less than 24 monthly observations.

${ }^{5}$ In addition, we assume that unclassifiable positions in capital insurance, derivatives, and fixed income securities are invested in the same mix of cash and stocks as the rest of liquid financial wealth. 
In the third stage, we convert the volatility into a risky share held in a single composite risky asset. The composite asset, also called numeraire, is the aggregate portfolio of Swedish households, scaled to have the same volatility as the after-tax MSCI world index: $R_{N, t+1}^{e}=(1+L)\left(\omega_{\text {agg },}^{\prime} R_{\text {agg,t+1 }}^{e}\right)$. Here $R_{N, t+1}^{e}$ is the return on the numeraire and $\omega_{\text {agg,t }}$ is the vector containing the weights of equity, real estate and risky DC wealth in the aggregate non-cash net wealth of all Swedish households in our sample. The scaling factor $L$ is chosen so that the volatility of $R_{N, t+1}^{e}$ is equal to the volatility of the after-tax return in local currency on the global equity index.

Total net wealth earns the excess return $R_{h, t+1}^{e}=\left(N C W_{h, t} / W_{h, t}\right) R_{N C W, h, t+1}^{e}$. The empirical risky share $\alpha_{h, t}$ is the ratio of the standard deviation of household $h$ 's overall portfolio to the standard deviation of the numeraire asset:

$$
\alpha_{h, t}=\frac{\sigma\left(R_{h, t+1}^{e}\right)}{\sigma\left(R_{N, t+1}^{e}\right)}=\left(\frac{N C W_{h, t}}{W_{h, t}}\right) \frac{\sigma\left(R_{N C W, h, t+1}^{e}\right)}{\sigma\left(R_{N, t+1}^{e}\right)} .
$$

This approach implicitly assumes that all households earn the same Sharpe ratio on their risky assets, but guarantees that the standard deviation of a household's wealth return used in our simulations coincides with its empirical value. A unit value for $\alpha_{h, t}$ says that the portfolio has the same volatility, $13.3 \%$, as if it is invested solely in the MSCI world stock index outside a retirement account.

\subsection{Composite Households}

We consider Swedish households aged between 40 and 60 during the 1999 to 2007 period. There are 7.7 million household-year observations on the 13 cohorts born between 1947 and 1959, but we impose several filters. We exclude 2.3 million observations on households that do not hold risky financial assets outside retirement 
accounts. We also exclude households in which the head is a student, working in the agricultural sector, retired before 1999, missing information on education or sector of employment, or missing data in any year. We exclude households that change their employment sector during our sample in such a way as to alter the level of income volatility they are exposed to. Since our measurement procedures may be less adequate for the wealthiest, we also exclude households whose financial wealth is above the 99th percentile of the wealth distribution in 1999. These filters exclude another 2.7 million observations, leaving us with a balanced panel containing 2.7 million household-year observations and 298,540 households.

We classify households by three levels of educational attainment: (i) basic or missing, (ii) high school, and (iii) post-high school. We also classify households by 12 sectors of employment. Within each education level, we rank the sectors by their total income volatility and divide them in three categories. We obtain a $3 \times 3$ grid of 9 large education/sector categories where the sectors of employment are aggregated by income volatility. We subdivide each of these categories using a two-way sort by deciles of the initial wealth-income ratio and initial risky share. We use the lowest two and highest two deciles and the middle three quintiles, giving us a $7 \times 7$ grid of 49 bins for the initial wealth-income ratio and risky share 6 Finally, we again subdivide by 13 cohorts to create $5733=9 \times 49 \times 13$ groups. After excluding groups with less than 10 members or a wealth-income ratio higher than 25 in each year from 1999 to 2007, our final sample is a balanced panel of 4276 groups.

The median group size across years is 53 households, but the average group size is larger at about 70 households. The difference reflects a right-skewed distribution

\footnotetext{
${ }^{6}$ The wealth-income and risky share breakpoints are set separately in each of the 9 categories. This ensures that across categories we have the same proportion of households at each of the 7 risky share and wealth-income levels. However, the number of households can differ across the 49 bins defined by the two-way sort.
} 
Table 1: Wealth-Income Ratio and Risky Share by Education and Income Risk

Panel A. Cross-Sectional Means

\begin{tabular}{lcccccccc}
\hline \hline & \multicolumn{4}{c}{ WY } & \multicolumn{4}{c}{ RS } \\
& $\begin{array}{l}\text { No High } \\
\text { School }\end{array}$ & $\begin{array}{c}\text { High } \\
\text { School }\end{array}$ & $\begin{array}{c}\text { Post-High } \\
\text { School }\end{array}$ & All & No High & High & Post-High & \\
& 3.70 & 4.13 & 5.08 & 4.47 & 0.692 & 0.686 & 0.675 & 0.682 \\
Low & 4.52 & 4.50 & 4.94 & 4.68 & 0.665 & 0.672 & 0.660 & 0.666 \\
Medium & 4.50673 & School & School & All \\
High & 4.74 & 5.10 & 6.15 & 5.47 & 0.670 & 0.675 & 0.673 & 0.673 \\
All & 4.25 & 4.51 & 5.27 & 4.79 & 0.677 & 0.678 & 0.669 & 0.674 \\
\hline \hline
\end{tabular}

Panel B. Cross-Sectional Standard Deviations

\begin{tabular}{|c|c|c|c|c|c|c|c|c|}
\hline & \multicolumn{4}{|c|}{$\mathrm{WY}$} & \multicolumn{4}{|c|}{$\mathrm{RS}$} \\
\hline & $\begin{array}{c}\text { No High } \\
\text { School }\end{array}$ & $\begin{array}{c}\text { High } \\
\text { School }\end{array}$ & $\begin{array}{c}\text { Post-High } \\
\text { School }\end{array}$ & All & $\begin{array}{c}\text { No High } \\
\text { School }\end{array}$ & $\begin{array}{c}\text { High } \\
\text { School }\end{array}$ & $\begin{array}{c}\text { Post-High } \\
\text { School }\end{array}$ & All \\
\hline Low & 3.06 & 3.27 & 3.58 & 3.42 & 0.249 & 0.227 & 0.203 & 0.221 \\
\hline Medium & 3.69 & 3.56 & 3.77 & 3.67 & 0.249 & 0.228 & 0.210 & 0.224 \\
\hline High & 3.87 & 3.85 & 3.90 & 3.92 & 0.238 & 0.220 & 0.189 & 0.211 \\
\hline All & 3.53 & 3.55 & 3.76 & 3.66 & 0.246 & 0.226 & 0.203 & 0.220 \\
\hline
\end{tabular}

Panel A reports cross-sectional means of the wealth-income ratio (WY) and risky share (RS) for Swedish household groups with 3 levels of education and working in sectors with 3 levels of income volatility given in Appendix Tables A.2 and A.3 and for aggregates of these groups. Panel B reports cross-sectional standard deviations of WY and RS across the groups in each of these categories and their aggregates. All statistics are based on the 1999 to 2007 period and weight groups by their size, that is by the number of households they contain, to recover the underlying household-level statistics assuming homogeneity of WY and RS within groups. Summary statistics on group size are reported in Appendix Table A.1

of group size, with many small groups and a few much larger ones. The group-level statistics we report in the paper are all size-weighted in order to reflect the underlying distributions of data and preference parameters at the household level.

We treat each group as a composite household, adding up all wealth and income of households within the group. Because we assume scale-independent Epstein-Zin preferences, we scale wealth by income and work with the wealth-income ratio as well as the implied risky share held in our composite numeraire asset. 


\subsection{Cross-Section of Wealth-Income Ratio and Risky Share}

We now consider the cross-section of the wealth-income ratio and risky share, averaging across all years in our sample. The top panel of Table 11 shows the variation in average wealth-income ratios and risky portfolio shares across groups, averaging across cohorts and the subdivisions by initial wealth-income ratio and risky share. Households in each group are treated as a single composite household that owns all wealth and receives all income of the group, and groups are weighted by the number of households they contain. Average wealth-income ratios vary widely from 3.7 to 6.2 , while average risky shares vary in a narrow range from $66 \%$ to $69 \%$. Within each sector, average wealth-income ratios are higher for more educated households, particularly those with post-high school education, but average risky shares vary little with education. Across sectors, income risk has a strong positive effect on the wealth-income ratio and a weak effect on the risky share.

The bottom panel of Table 1 reports the standard deviations of the wealth-income ratio and the risky portfolio share across groups in each of the nine categories of education and sectoral income risk. The standard deviations of the risky share are consistently in the range $19-25 \%$, while the standard deviations of the wealth-income ratio are in the range 3.0-3.9. Across all 4276 groups, the average wealth-income ratio has a mean of 4.8 with a standard deviation of 3.7, while the average risky share has a mean of $67 \%$ with a standard deviation of $22 \% .7$

The cross-sectional variation in wealth and asset allocation documented in Table 1 suggests that it will be difficult to account for household behavior without allowing for heterogeneity in preferences. We now develop a life-cycle model that we can use to estimate preferences from the evolution of wealth and asset allocation.

${ }^{7}$ Figure A.1 in the online appendix plots the size-weighted group-level distributions. 


\section{Income Process and Life-Cycle Model}

\subsection{Measuring Income Risk}

We consider the labor income specification used in Carroll and Samwick (1997), Gourinchas and Parker (2002) and Cocco, Gomes, and Maenhout (2005), among others:

$$
\log \left(Y_{h, t}\right)=a_{c}+b^{\prime} x_{h, t}+v_{h, t}+\varepsilon_{h, t}
$$

where $Y_{h, t}$ denotes real income for household $h$ in year $t, a_{c}$ is a fixed effect for the cohort to which the household belongs, $x_{h, t}$ is a vector of characteristics, $v_{h, t}$ is a permanent random component of income, and $\varepsilon_{h, t}$ is a transitory component.

We enrich the model above by distinguishing between shocks that are common to all households in a group and shocks that are specific to each household in the group. We assume that the permanent component of income, $v_{h, t}$, is the sum of a group-level component, $\xi_{t}$, and an idiosyncratic component, $z_{h, t}$ :

$$
v_{h, t}=\xi_{t}+z_{h, t}
$$

To simplify notation, we do not write an explicit group index but write group-level shocks using a single time index. The components $\xi_{t}$ and $z_{h, t}$ follow independent random walks: $\xi_{t}=\xi_{t-1}+u_{t}$, and $z_{h, t}=z_{h, t-1}+w_{h, t}$.

The transitory component of income, $\varepsilon_{h, t}$, is by contrast purely idiosyncratic. This fits the fact that group average income growth in our Swedish data is slightly positively autocorrelated, whereas it would be negatively autocorrelated if transitory income had a group-level component. Finally, we assume that the three income 
shocks impacting household $h$ are i.i.d. Gaussian: $\left(u_{t}, w_{h, t}, \varepsilon_{h, t}\right)^{\prime} \sim \mathcal{N}\left(0, \Omega_{Y}\right)$, where $\Omega_{Y}$ is the diagonal matrix with diagonal elements $\sigma_{u}^{2}, \sigma_{w}^{2}$, and $\sigma_{\varepsilon}^{2}$.

We estimate the income process (5) using household yearly income data, following a procedure described in the appendix. This gives us estimates of the age-income profile for each education group, which we plot in appendix Figure A.2.

To estimate income risk, we further divide households with the same education level into business sector categories. $\sigma_{u}^{2}$ is estimated by averaging the regression residuals within each education-business sector category, and by computing the sample variance of the resulting income innovations. We then apply a Carroll and Samwick (1997) decomposition to estimate the permanent and transitory idiosyncratic income risks, $\sigma_{w}^{2}$ and $\sigma_{\varepsilon}^{2}$, of each education-business sector category.

We proceed in two steps. First, we implement the procedure above on 36 education-business sector categories obtained by dividing households with each of three education levels into the 12 business sectors corresponding to the first digit of the SNI industry code. Equipped with income risk estimates for each of the 36 categories, we aggregate business sectors into three levels of total income risk for each education level 8 Second, we re-apply the procedure above to estimate income risk for the resulting nine education-business sector categories.

Appendix Table A.3 reports the standard deviations estimated for these nine categories. Permanent (systematic and idiosyncratic) income volatilities vary relatively little across sectors, but transitory idiosyncratic income volatilities are considerably higher for high-risk sectors. The table also shows that educated households, particularly those with higher education, face higher transitory income risk and lower

\footnotetext{
${ }^{8}$ Appendix Table A.1 reports the number of households and Table A.2 reports the underlying sectors in each category.
} 
idiosyncratic permanent income risk than less educated households. This pattern is consistent with Low, Meghir, and Pistaferri (2010), but it contrasts with earlier studies showing the opposite pattern in the US. A likely explanation is that in Sweden, uneducated workers face lower unemployment risk and lower effects of unemployment on income than in many other countries, while educated workers face relatively high income losses when they become unemployed.9

We have already noted in discussing Table 1 that average wealth-income ratios tend to be higher in sectors with riskier income. This pattern is intuitive given that labor income risk encourages precautionary saving. However, there is little tendency for risky portfolio shares to be lower in sectors with riskier income.

Table 2 further explores these effects by regressing the average wealth-income ratio and risky share on age, total income volatility, and dummies for high school and post-high school education. All regressions also include year fixed effects. The first column of the table shows that the average wealth-income ratio increases with age and with income volatility. This is consistent with the view that wealth is accumulated in part to finance retirement, and in part as a buffer stock against temporary shocks to income. In addition, the average wealth-income ratio increases with the level of education.

The second column shows that the average risky share decreases with age, but income risk and education are not significant predictors of the average risky share although the coefficient on income risk is negative as one might expect. The third column adds the wealth-income ratio as a predictor for the risky share, and finds a negative effect. After controlling for the wealth-income ratio, income risk has a significantly positive effect on the risky share. This finding suggests that households

\footnotetext{
${ }^{9}$ This results from institutional features of the Swedish labor market which we explain in the online appendix.
} 
Table 2: Panel Regressions of Wealth-Income Ratio and Risky Share on Group Characteristics

\begin{tabular}{lccc}
\hline \hline & $(1)$ & $(2)$ & $(3)$ \\
& $\mathrm{WY}$ & $\mathrm{RS}$ & $\mathrm{RS}$ \\
\hline Age & $0.156^{* * *}$ & $-0.014^{* * *}$ & $-0.010^{* * *}$ \\
& $(0.016)$ & $(0.001)$ & $(0.001)$ \\
Total income volatility & $15.755^{* * *}$ & -0.151 & $0.288^{* *}$ \\
& $(1.891)$ & $(0.111)$ & $(0.092)$ \\
High school & $0.478^{* * *}$ & -0.010 & 0.003 \\
& $(0.136)$ & $(0.009)$ & $(0.007)$ \\
Post-high school & $1.044^{* * *}$ & $-0.016^{*}$ & 0.013 \\
& $(0.138)$ & $(0.008)$ & $(0.007)$ \\
WY & & & $-0.028^{* * *}$ \\
& & & $(0.001)$ \\
Constant & $-6.331^{* * *}$ & $1.532^{* * *}$ & $1.356^{* * *}$ \\
& $(0.785)$ & $(0.053)$ & $(0.043)$ \\
Year fixed effects & Yes & Yes & Yes \\
\hline$R^{2}$ & 0.103 & 0.189 & 0.382 \\
\hline \hline
\end{tabular}

This table reports panel regressions of the wealth-income ratio (WY) and risky share (RS) on group characteristics including the age of households in the group, total income volatility (in natural units), and dummies for high-school and post-high-school education. All regressions weight groups by their size, to recover underlying relationships at the household level, and include year fixed effects. Standard errors are reported in parentheses and statistical significance levels are indicated with stars: $*$ denotes $1-5 \%, * * 0.1-1 \%$, *** less than $0.1 \%$ significance. There are 38,484 observations on groups, corresponding to $2,686,860$ observations on underlying households.

with risky income tend to have lower risk aversion, as Section 4.2 will confirm.

The negative effects of age and the wealth-income ratio on the risky share are consistent with the predictions of a simple static model in which labor income is safe and tradable, so that human capital is an implicit cash holding that tilts the composition of the financial portfolio towards risky assets (Bodie, Merton, and Samuelson 1992, Campbell and Viceira 2002) 10 We work with a richer lifecycle

\footnotetext{
${ }^{10}$ The negative effect of the wealth-income ratio on the risky share appears to contradict evidence that wealthier individuals take more financial risk (Carroll 2002, Wachter and Yogo 2010, Calvet and Sodini 2014). The discrepancy is likely due to several factors. Our sample excludes non-participants in risky financial markets and the wealthiest $1 \%$ of Swedish households in 1999; we measure the risky portfolio share taking account of housing and leverage through mortgage borrowing; and we
} 
model in which labor income is risky and nontradable, but that model implies a similar pattern of age and wealth effects on the risky share.

\subsection{Life-Cycle Model}

We consider a standard life-cycle model, very similar to the one in Cocco, Gomes and Maenhout (2005) and Gomes and Michaelides (2005). Households have finite lives and Epstein-Zin utility over a single consumption good. The utility function $V_{t}$ is specified by the RRA coefficient $\gamma$, the time discount factor $\delta$ or equivalently the TPR $-\log (\delta)$, and the EIS $\psi$. The utility $V_{t}$ satisfies the recursion

$$
V_{t}=\left[C_{t}^{1-1 / \psi}+\delta\left(\mathbb{E}_{t} p_{t, t+1} V_{t+1}^{1-\gamma}\right)^{(1-1 / \psi) /(1-\gamma)}\right]^{\frac{1}{1-1 / \psi}}
$$

where $p_{t, t+1}$ denotes the probability that a household is alive at age $t+1$ conditional on being alive at age $t$, calibrated from Sweden's life tables. Preference parameters vary across households but we suppress the household index in (7) for simplicity.

The wealth accumulation of young households is significantly influenced by housing purchases, transfers from relatives, investments in education, or changes in family size, which for tractability we do not include in our model. Similarly, matching the behavior of retirees is also hard for simple life-cycle models that do not incorporate health shocks or bequest motives. 11 For these reasons, we only consider the model's implications for ages 40 to 60 .

We initialize the model at age 40. The time index in the model, $t$, starts at 1 , so

predict the risky share using the wealth-income ratio rather than the absolute level of wealth.

${ }^{11}$ Since we do not observe decisions late in life, we do not include an explicit bequest motive and instead capture the desire to leave a bequest as a lower TPR. 
that $t$ is calendar age minus 39. Each period corresponds to one year and agents live for a maximum of $T=61$ periods (corresponding to age 100). Before retirement households supply labor inelastically. The stochastic process of labor income, $Y_{h, t}$, is described in Section 2.1. All households retire at age 65, as was typically the case in Sweden during our sample period, and retirement earnings are set to a constant replacement ratio of the last working-life permanent income. Consistent with Section 1, wealth in the model is invested every period in a one-period riskless asset (bond) and a composite risky asset.

The household chooses its consumption level $C_{h, t}$ and risky portfolio share $\alpha_{h, t}$ subject to a constraint that financial wealth is positive- that is, the household cannot borrow to finance consumption. We do allow borrowing to finance a risky asset position, that is, we allow $\alpha_{h, t} \geq 1$. Household wealth satisfies the budget constraint

$$
W_{h, t+1}=\left(R_{f}+\alpha_{h, t} R_{N, t+1}^{e}\right)\left(W_{h, t}+Y_{h, t}-C_{h, t}\right)
$$

where $R_{N, t+1}^{e}$ is the return on the composite numeraire asset in excess of the gross risk free rate $R_{f}$. The excess return $R_{N, t+1}^{e}$ is Gaussian $\mathcal{N}\left(\mu_{r}, \sigma_{r}^{2}\right)$.

\subsection{Calibrated Parameters}

The parameters of our life-cycle model can be divided into those describing the income process, and those describing the properties of asset returns. For income, we have age profiles and retirement replacement ratios as illustrated in appendix Figure A.2, and the standard deviations $\sigma_{u}, \sigma_{w}$, and $\sigma_{\varepsilon}$ in appendix Table A.3.

We assume that all safe borrowing and lending takes place at a single safe interest 
rate of $2.0 \% .12$ We set the volatility of the numeraire risky asset at $13.3 \%$, which is equal to the volatility of post-tax excess stock returns as discussed in section 1.2 . We assume that the average excess return on the numeraire asset over the safe interest rate is $3.5 \%$, the same as the average post-tax equity premium on the MSCI world index in local currency over the period 1984-2007. Putting these assumptions together, we assume a Sharpe ratio of 0.26. In section 4.5 we discuss robustness of our results to assuming alternative Sharpe ratios.

Following Campbell, Cocco, Gomes, and Maenhout (2001), we estimate the correlation between the numeraire risky asset return and group-level systematic income shocks by lagging the stock return one year to capture a delayed response of income to macroeconomic shocks that move asset prices immediately. Empirically the correlation has an average value across the nine education-sector categories of 0.08 for stock returns, 0.37 for real estate returns, and 0.26 for the composite risky asset.13 In the appendix Table A.4 we report the separate correlations for each of the nine categories that we use in our model.

\section{Identification and Estimation}

Our goal is to estimate the three preference parameters of the Epstein-Zin utility model. The main challenge is that the TPR and the EIS are not separately identified

\footnotetext{
${ }^{12}$ This is calibrated as a weighted average of a safe lending rate of $0.8 \%$ and the average household borrowing rate of $3.6 \%$, using the cross-sectional average household debt level to construct the average. Moreover, our model would allow us to assume that households pay a higher rate when they have a risky share greater than one. However, this assumption would not be a better approximation to reality than the one we make, since households who borrow to buy housing pay the borrowing rate even when their risky share is below one.

${ }^{13}$ The correlation between the numeraire risky asset return and individual income growth is much smaller because most individual income risk is idiosyncratic.
} 
if consumption growth and the portfolio return are independent and identically distributed, as Kocherlakota (1990) and Svensson (1989) explain.

The online appendix suggests three possible solutions in our context. One channel is endogenous variation in savings driven by time variation in the wealthincome ratio. The second channel is time variation in the expected portfolio return. Even though our model has no exogenous variation in expected asset returns, age drives endogenous changes in the risky share. The third channel is age variation in the survival probabilities $p_{t, t+1}$ and therefore the effective time discount factor $\delta p_{t, t+1}$. These sources of variation imply that the profile of the wealth-income ratio is affected in different ways by the TPR and the EIS, at different ages. In the appendix (section 2 and Table A.5), we confirm the good identification of the preference parameters in simulated data.

\subsection{Indirect Inference Estimator}

The estimation of the vector of preference parameters, $\theta^{g}=\left(\delta^{g}, \gamma^{g}, \psi^{g}\right)^{\prime}$, in each group $g$ proceeds by indirect inference (Smith 1993, Gouriéroux, Monfort, and Renault 1993). This method compares a vector of auxiliary statistics produced by the lifecycle model to the vector of empirical auxiliary statistics in the group. We denote by $p=3$ the number of components of $\theta^{g}$, by $N^{g}$ the number of households in the group, and by $T=8$ the number of years in the panel.

For every $t \in\{1, \ldots, T\}$, we consider the following auxiliary statistics: (i) the wealth-income ratio of the group, defined as the ratio of the group's total wealth to the group's total income:

$$
\hat{\mu}_{1, t}^{g}=\frac{\sum_{h=1}^{N^{g}} W_{h, t}}{\sum_{h=1}^{N^{g}} Y_{h, t}},
$$


and (ii) the group's risky share:

$$
\hat{\mu}_{2, t}^{g}=\frac{\sum_{h=1}^{N^{g}} \alpha_{h, t} W_{h, t}}{\sum_{h=1}^{N^{g}} W_{h, t}} .
$$

These statistics provide reliable measures of wealth accumulation and risk-taking based on group aggregates. We note that $\hat{\mu}_{1, t}^{g}$ and $\hat{\mu}_{2, t}^{g}$ are ratios of sample moments but are not sample moments themselves, which motivates the use of indirect inference rather than moment-based estimators. We stack auxiliary statistics into the empirical auxiliary estimator $\hat{\mu}^{g}=\left(\hat{\mu}_{1,1}^{g}, \ldots, \hat{\mu}_{1, T}^{g}, \hat{\mu}_{2,1}^{g}, \ldots, \hat{\mu}_{2, T}^{g}\right)^{\prime}$. By construction, $\hat{\mu}^{g}$ has $q=16$ components. 14

The data-generating process is based on the policy functions of households with preference parameter vector $\theta$, the return process, and the labor income process defined in earlier sections. As the number of households in the group goes to infinity, the empirical auxiliary estimator $\hat{\mu}^{g}$ converges to the binding function $\mu^{g}(\theta) \in \mathbb{R}^{q}$ with components $\mu_{1, t}^{g}(\theta)=\mathrm{E}_{\theta}^{g}\left(W_{t}\right) / \mathrm{E}_{\theta}^{g}\left(Y_{t}\right)$ and $\mu_{2, t}^{g}(\theta)=\mathrm{E}_{\theta}^{g}\left(\alpha_{t} W_{t}\right) / \mathrm{E}_{\theta}\left(W_{t}\right)$, where $\mathrm{E}_{\theta}^{g}(\cdot)$ denotes the cross-sectional mean of households in the group. These expectations are computed under the assumption that all households earn the riskfree rate $R_{f}$ and the synthetic excess risky return $R_{N, t}^{e}$ on their risky asset holdings.

We estimate the binding function $\mu^{g}(\theta)$ by simulation of the life-cycle model as follows. For each preference parameter $\theta$, we compute the wealth-income ratio and risky share predicted by the model for the years 2000 to 2007 using the parameters from appendix Table A.3 as inputs. For each year $t$, the starting point is an information set $\mathcal{I}_{t}$ containing the empirical wealth-income ratio of group $g$ at the end of year $t-1$. In the simulations, we feed the realized return on the risky asset and the

\footnotetext{
${ }^{14}$ We could also include the risky share in the initial year $\left(\alpha_{i 0}\right)$, since it is also an endogenous moment from the simulations. We exclude it in order to have an equal number of auxiliary statistics related to the wealth-income ratio and to the risky share.
} 
realized empirical group-level income shocks, during the year. Consistent with the life-cycle model, we assume that households have this much advance information about wages and hours. We simulate the idiosyncratic permanent and transitory income shocks of each household, which we combine to $\mathcal{I}_{t}$ to obtain the group's wealth-income ratio and risky share at the end of year $t$. We denote the simulated values as $\tilde{\mu}_{1, t}^{g}(\theta)$ and $\tilde{\mu}_{2, t}^{g}(\theta)$, respectively, and stack them into a column vector $\tilde{\mu}_{S}^{g}(\theta)$. The appendix explains the simulation procedure in detail.

We estimate the vector of preference parameters by minimizing the deviation $\tilde{\mu}_{S}^{g}(\theta)-\hat{\mu}^{g}$ between the lifecycle model and the data:

$$
\hat{\theta}^{g}=\arg \min _{\theta}\left[\tilde{\mu}_{S}^{g}(\theta)-\hat{\mu}^{g}\right]^{\prime} \Omega\left[\tilde{\mu}_{S}^{g}(\theta)-\hat{\mu}^{g}\right] .
$$

We choose a diagonal weighting matrix $\Omega$ common to all groups. Each diagonal element of $\Omega$ is a scale factor that converts the wealth-income ratios and risky shares into comparable units. Specifically, we let $\Omega=\operatorname{diag}\left(\omega_{1}, \ldots, \omega_{1}, \omega_{2}, \ldots, \omega_{2}\right)$, where $\omega_{1}=\left(\frac{1}{G T} \sum_{g=1}^{G} \sum_{t=1}^{T} \hat{\mu}_{1, t}^{g}\right)^{-2}$ and $\omega_{2}=\left(\frac{1}{G T} \sum_{g=1}^{G} \sum_{t=1}^{T} \hat{\mu}_{2, t}^{g}\right)^{-2}$. These weights have $\left(\omega_{2} / \omega_{1}\right)^{1 / 2}=7.57$, consistent with an average risky share of around 0.5 and an average wealth-income ratio of 3.5. Using a common weighting matrix $\Omega$ implies that the objective function in (11) is comparable across groups.

If our model is correctly specified, the indirect inference estimator $\hat{\theta}^{g}$ is asymptotically consistent as the number of households in each group increases. We can also calculate the asymptotic variance-covariance matrix of our parameter estimates. Further details on the properties of our estimator are given in the appendix. 


\section{Empirical Results}

\subsection{The Cross-Sectional Distribution of Preference Estimates}

Tables 3 and 4 and Figure 1 summarize the cross-sectional distributions of our estimated preference parameters. Table 3 reports the cross-sectional means, medians, and standard deviations of the estimated parameters along with summary statistics of the data. Table 4 reports the cross-sectional correlations of the estimated parameters and summary statistics. A number of interesting patterns are visible in these tables.

Table 3 reports a mean RRA of 7.57, close to the median estimate of 7.50 and in the upper half of the range from 1 to 10 defined as reasonable by Mehra and Prescott (1985). The cross-sectional standard deviation of estimated RRA is modest at 1.06, less than $15 \%$ of the mean and median estimates.

The cross-sectional standard deviation of RRA is lower in proportional terms than the cross-sectional standard deviation of the risky portfolio share, which was shown in Table 1 to be almost one-third of its mean. In a simple one-period portfolio choice model without labor income, the risky portfolio share and RRA are inversely proportional to one another so they must have equal proportional standard deviations; and the same is true in a model where labor income is safe and can be borrowed against and all investors have the same wealth-income ratio. Two features of our model help to account for this finding. First, there is variation across groups in their wealth-income ratios which helps to account for some of the cross-sectional variation in risky shares as illustrated in Table 2. Second, we estimate that labor

income risk is correlated with financial risk; this increases the change in the risky financial share that is needed to generate a given change in a household's overall 
Table 3: Cross-Sectional Distributions of Estimated Preference Parameters and Group Financial Characteristics

\begin{tabular}{lccccccc}
\hline \hline & Mean & Median & Std. Dev. & $10 \%$ & $25 \%$ & $75 \%$ & $90 \%$ \\
\hline RRA & 7.57 & 7.50 & 1.06 & 6.30 & 6.90 & 8.00 & 8.90 \\
TPR (\%) & 5.21 & 3.15 & 6.96 & -1.09 & 1.21 & 6.19 & 18.87 \\
EIS & 0.96 & 0.50 & 0.90 & 0.10 & 0.17 & 1.81 & 2.50 \\
Average RS & 0.65 & 0.63 & 0.17 & 0.45 & 0.53 & 0.75 & 0.90 \\
Initial WY & 4.28 & 3.04 & 3.90 & 0.87 & 1.64 & 5.22 & 9.25 \\
Growth of WY & 1.08 & 1.07 & 0.05 & 1.03 & 1.05 & 1.10 & 1.14 \\
Convexity of WY & 0.24 & 0.23 & 0.09 & 0.15 & 0.19 & 0.28 & 0.35 \\
\hline \hline
\end{tabular}

This table reports the mean, median, standard deviation, and 10th, 25th, 75th, and 90th percentiles of estimated preference parameters and group financial characteristics. All statistics weight groups by their size to recover the underlying cross-sectional distributions at the household level. Growth of WY and convexity of WY are defined in equations (4) and (5) of the online appendix. There are 4,276 groups containing 298,540 households.

risk exposure.

The other two preference parameters have much greater cross-sectional variation relative to their means, and both are strongly right-skewed. The median TPR is $3.15 \%$, considerably lower than the mean of $5.21 \%$, and the cross-sectional standard deviation of the TPR is $6.96 \%$. Similarly, the median EIS is 0.50 , considerably lower than the mean of 0.96, and the cross-sectional standard deviation of the EIS is 0.90. This cross-sectional standard deviation is over 6 times as large for the EIS as for RRA in proportional terms; this contrasts with the prediction of a power utility model, which would imply equal proportional standard deviations for RRA and the EIS since one parameter is the reciprocal of the other. 15

Table 4 shows that preference parameter estimates are only weakly crosssectionally correlated. RRA and the EIS have a weak negative correlation of -0.11 , a finding that contrasts with the perfect negative correlation between the logs of RRA and the EIS under power utility. The TPR is positively correlated with RRA

\footnotetext{
${ }^{15}$ Appendix Figure A.3 plots the univariate distributions of all three preference parameters.
} 
Figure 1: Joint Distribution of TPR and EIS

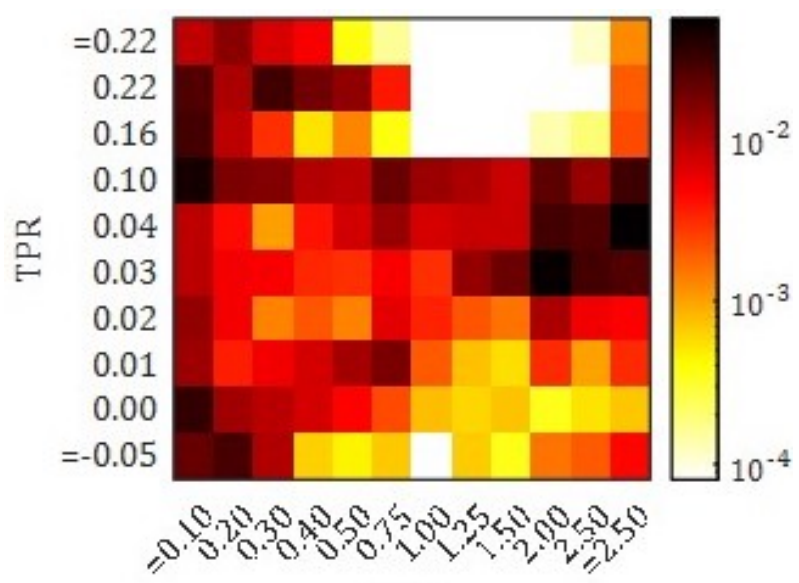

EIS

This figure presents bivariate heat map for estimates of TPR and EIS across 4,276 groups of Swedish households, size-weighted to recover the underlying distribution across households under the assumption that preferences are homogeneous within groups. Each axis label shows the upper cutoff value of the corresponding bin, except for labels beginning with $=$ which indicate that the bin contains only estimates of the exact value indicated by the label. The logarithmic color scheme indicates the fraction of the sample in each bin. This fraction is $9.6 \%$ for the darkest color and $0.0 \%$ for the brightest color.

and negatively correlated with the EIS, but the correlations are modest at 0.19 and -0.22 respectively. These weak correlations imply that heterogeneity in household preferences is multi-dimensional and cannot be explained by any single factor missing from our model such as heterogeneity in beliefs about the equity premium.

Figure 1 is a heat map of the bivariate distribution of the TPR and EIS. The distribution of the EIS is U-shaped, with probability mass concentrated below 1 and near the upper edge of our parameter space which we set to 2.5. The distribution of the TPR is also dispersed, but the figure shows that more extreme values of the TPR are associated with low values of the EIS. This makes sense since a low EIS reduces the impact of the TPR on observable savings decisions.

The online appendix conducts a Monte Carlo analysis of our procedure. A 
Table 4: Cross-Sectional Correlations of Estimated Preference Parameters and Group Financial Characteristics

\begin{tabular}{lcccccc}
\hline \hline & RRA & TPR & EIS & $\begin{array}{c}\text { Average } \\
\text { RS }\end{array}$ & $\begin{array}{c}\text { Initial } \\
\text { WY }\end{array}$ & $\begin{array}{c}\text { Growth } \\
\text { of WY }\end{array}$ \\
\hline RRA & 1.000 & & & & & \\
TPR & $0.191^{* * *}$ & 1.000 & & & & \\
EIS & $-0.114^{* * *}$ & $-0.217^{* * *}$ & 1.000 & & & \\
Average RS & $-0.124^{* * *}$ & $0.561^{* * *}$ & $-0.065^{* * *}$ & 1.000 & & \\
Initial WY & $-0.483^{* * *}$ & $-0.461^{* * *}$ & $0.387^{* * *}$ & $-0.501^{* * *}$ & 1.000 & \\
Growth of WY & $0.321^{* * *}$ & $0.539^{* * *}$ & $-0.116^{* * *}$ & $0.600^{* * *}$ & $-0.709^{* * *}$ & 1.000 \\
\hline \hline
\end{tabular}

This table reports the cross-sectional correlations across estimated preference parameters and group financial characteristics. Correlations weight groups by their size to recover the underlying crosssectional correlations at the household level. Growth of WY is defined in equation (4) of the online appendix. Statistical significance levels of correlation coefficients are indicated with stars: * denotes $1-5 \%$, ** $0.1-1 \%$, *** less than $0.1 \%$ significance. There are 4,276 groups containing 298,540 households.

key lesson is that small-sample bias cannot explain the substantial cross-sectional heterogeneity in our preference estimates. There is almost no bias for the RRA, minimal bias for the TPR, and some bias for the EIS, but correcting this bias has little effect on cross-sectional parameter dispersion.

\subsection{Preference Estimates and Household Characteristics}

The lower portion of Table 4 explores correlation patterns among preference parameters and observables. The initial wealth-income ratio has a correlation of -0.50 with the average risky share and a correlation of -0.71 with the average growth rate of the wealth-income ratio. These correlations are consistent with the predictions of our life-cycle model that the risky share declines with the level of financial wealth in relation to human capital, and that households that enter the sample with low financial wealth have a strong motive to accumulate wealth to finance retirement. Correspondingly, the average risky share and the average growth rate of the wealth-income ratio have a positive correlation of 0.60 . 
Our estimate of RRA is weakly negatively correlated (-0.12) with the average risky share, an intuitive result that is consistent with our identification analysis. RRA is more strongly negatively correlated $(-0.48)$ with the initial wealth-income ratio. Mechanically, this reflects the fact that households who enter the sample with high wealth have risky shares that are insufficiently lower than the risky shares of other households to be consistent with the same level of RRA.

Our estimate of the TPR is negatively correlated $(-0.46)$ with the initial wealthincome ratio and positively correlated $(0.53)$ with the average growth rate of the wealth-income ratio in our sample period. Mechanically, this is due to the fact that households that enter our sample with low initial wealth accumulate wealth more rapidly than average households, but not as rapidly as they would do if they had an average TPR. It is intuitive that impatient households accumulate less wealth before age 40 and then belatedly catch up as retirement approaches. The TPR is also positively correlated $(0.56)$ with the average risky share, reflecting the lower wealthincome ratio of impatient households that justifies a riskier investment strategy.

Our estimate of the EIS is positively correlated (0.39) with the initial wealthincome ratio and weakly negatively correlated $(-0.12)$ with the average growth rate of the wealth-income ratio. Economically, this suggests that households with a high EIS save for retirement early in life, before our sample begins; such households have a high willingness to adjust consumption to reach their target wealth-income ratio, whereas households with a low EIS save more gradually over time 16

We next ask how our estimates are related to households' income risk and education. Table 5 regresses preference estimates on labor income volatility, the

${ }^{16}$ Appendix Table A.6 reports multiple regressions rather than univariate correlations. Most patterns are similar, but controlling for the initial wealth-income ratio, the growth of wealth-income predicts the EIS positively rather than negatively. 
Table 5: Education, Income Risk and Preferences

\begin{tabular}{lccc}
\hline \hline & $(1)$ & $(2)$ & $(3)$ \\
& RRA & TPR & EIS \\
\hline Total income & $-11.029^{* * *}$ & $-0.227^{* * *}$ & $1.980^{* * *}$ \\
volatility & $(0.465)$ & $(0.042)$ & $(0.542)$ \\
High school & $1.525^{* * *}$ & $0.037^{* * *}$ & $-0.196^{* * *}$ \\
& $(0.037)$ & $(0.003)$ & $(0.040)$ \\
Post-high school & $0.632^{* * *}$ & $0.017^{* * *}$ & $-0.155^{* * *}$ \\
& $(0.030)$ & $(0.003)$ & $(0.038)$ \\
Constant & $8.922^{* * *}$ & $0.105^{* * *}$ & $0.775^{* * *}$ \\
& $(0.096)$ & $(0.010)$ & $(0.120)$ \\
Cohort dummies & Yes & Yes & Yes \\
\hline$R^{2}$ & 0.352 & 0.085 & 0.023 \\
\hline \hline
\end{tabular}

This table reports the cross-sectional regression coefficients across estimated preference parameters and group characteristics including the total income volatility (in natural units), and dummies for high-school and post-high-school education. All regressions weight groups by their size, to recover the underlying cross-sectional relationships at the household level. Standard errors are reported in parentheses and statistical significance levels are indicated with stars: * denotes 1-5\%, ** 0.1-1\%, *** less than $0.1 \%$ significance. There are 4,276 groups containing 298,540 households.

level of education, and cohort fixed effects. RRA is most strongly related to these observables. Households with riskier labor income tend to have lower risk aversion. Mechanically, this results from the fact documented in Table 2 that income volatility has little effect on the risky share: if risk aversion were the same for safe and for risky occupations, then the risky share should fall with income risk. The finding suggests that risk-tolerant individuals self-select into risky occupations, or that households fail to fully understand the importance of income risk for investment. Controlling for income risk, more educated people tend to have slightly higher RRA. The $R^{2}$ of the regression for risk aversion is $35 \%$. Households with high income risk also tend to have a lower TPR and higher EIS, but the explanatory power of the TPR regression is less than $9 \%$ and that of the EIS regression is only $2 \%$. We do not find that educated households are more patient; in fact, they tend to have slightly higher TPR controlling for their income risk. 
We have reported size-weighted averages of preference parameters across groups, corresponding to equally weighted averages across households. While this is the natural weighting scheme in household finance applications, wealthier households have a greater influence on equilibrium asset prices and so asset pricing economists may be interested in wealth-weighted average preference parameters of households. In appendix Table A.7, we weight groups by their average wealth during the sample period rather than by their size. We find a similar mean risk aversion of 7.14, a much lower mean time preference rate of $2.63 \%$, and a somewhat higher mean EIS of 1.19. The cross-sectional standard deviations of these parameters are similar to the equally weighted case.

\subsection{Parameter Uncertainty}

The discussion in the previous subsections treats our point estimates of parameters as if they are equivalent to the parameters themselves. In this subsection we use our asymptotic standard errors to take parameter uncertainty into account.

In Table 6 we report hypothesis tests based on our asymptotic standard errors and using 5\% significance levels. We report that $13 \%$ of households are in groups estimated to have a negative TPR, but we can reject the null of a positive TPR for only $6 \%$ of households. Thus, a significantly negative TPR is a relatively rare occurrence in our sample. Conversely, we can reject the null of a negative TPR for $51 \%$ of households, and the null of a zero TPR using a two-sided test for $52 \%$ of households. Thus the TPR is significantly positive for a slight majority of Swedes.

The table reports that $61 \%$ of households are in groups with estimated EIS less than one. We can reject the null of an EIS greater than one for $44 \%$ of households, 
Table 6: Statistical Test Results for Estimated Preference Parameters

\begin{tabular}{lclc}
\hline \hline Condition & \% of Pop. & Condition & \% of Pop. \\
\hline TPR $<0$ & 13.3 & Reject RRA = mean(RRA) & 84.4 \\
Reject TPR $>0$ & 6.4 & Reject TPR = mean(TPR) & 45.1 \\
Reject TPR $<0$ & 50.5 & Reject EIS = mean(EIS) & 55.7 \\
Reject TPR =0 & 52.0 & Reject joint equality to mean & 98.5 \\
EIS $<1$ & 60.5 & Reject RRA = median(RRA) & 82.7 \\
Reject EIS $>1$ & 44.2 & Reject TPR = median(TPR) & 32.7 \\
Reject EIS $<1$ & 15.1 & Reject EIS = median(EIS) & 46.4 \\
Reject EIS $=1$ & 56.2 & & \\
EIS $<$ 1/RRA & 22.3 & & \\
Reject EIS $>1 /$ RRA & 0.8 & & \\
Reject EIS $<$ 1/RRA & 34.4 & & \\
Reject EIS $=1 /$ RRA & 30.7 & & \\
\hline \hline
\end{tabular}

This table reports the size-weighted fraction of Swedish household groups, or equivalently the fraction of Swedish households, for which each condition stated in the row label applies. All hypothesis test rejections are at the 5\% significance level. Hypothesis tests in the bottom panel treat the cross-sectional median preference parameter as known rather than estimated. There are 4,276 groups containing 298,540 households.

and can reject the null of an EIS less than one for only $15 \%$ of households. 17 Thus it is far more common for Swedish households to have an EIS significantly below one than an EIS significantly above one.

Turning to power utility, $22 \%$ of households have an estimated EIS that is lower than the reciprocal of RRA. We reject the null that EIS exceeds 1/RRA for only $1 \%$ of households, and reject the null that the EIS is lower than 1/RRA for $34 \%$ of households. A two-sided test rejects the power utility null for $31 \%$ of households.

We also test hypotheses about the heterogeneity of preferences. We report that $84 \%$ of households are in groups for which we can reject the null that the group RRA equals the cross-sectional mean RRA, taking account of statistical uncertainty about

${ }^{17}$ The asymmetry reflects the fact, illustrated in appendix Figure A.4, that the asymptotic standard error of the EIS is positively correlated with the level of the estimated EIS. 
that mean. Similarly, we reject equality to the mean TPR for $45 \%$ of households, and equality to the mean TPR for $56 \%$ of households. We can reject the null that all three parameters equal their cross-sectional means for $99 \%$ of households. Results are similar when we test whether group preference estimates equal the cross-sectional medians, treating the medians as known for simplicity. Overall, the table presents strong statistical evidence against homogeneity of preferences within our framework.

\subsection{Model Fit}

As appendix Figure A.5 shows, our model captures well the average variation of the risky share and wealth-income over the life-cycle, the usual target for life-cycle models. In this subsection we consider group-level measures of model fit. We begin by describing the cross-sectional distribution of the errors our model makes in fitting the 16 auxiliary statistics that are the target of our estimation procedure. We take the 8 wealth-income ratios and the 8 risky shares, and for each of these variables we calculate the root mean squared error (RMSE), the square root of the average squared deviation of the model-fitted variable from the observed variable. The results are reported in percentage points in the first two rows of Table 7 .

The mean RMSE across all groups is $31.9 \%$ for the wealth-income ratio and $5.0 \%$ for the risky share. In other words, the average error in fitted wealth is just under 4 months of income and the average error in the risky share is about $5 \%$ of wealth. The RMSE distribution is somewhat right-skewed as indicated by the fact that the median RMSEs are below the mean RMSEs at $22.1 \%$ and $4.1 \%$ respectively.

To interpret these numbers, we note that the RMSE of an atheoretical random walk model for WY has an average across groups of $33.0 \%$ and a median of $30.4 \%$. 
Table 7: Cross-Sectional Distributions of Model Fit Indicators

\begin{tabular}{lccccccc}
\hline \hline & Mean & Median & Std. Dev. & $10 \%$ & $25 \%$ & $75 \%$ & $90 \%$ \\
\hline WY RMSE & 31.89 & 22.10 & 30.82 & 9.93 & 14.24 & 38.27 & 67.18 \\
RS RMSE & 4.96 & 4.09 & 4.17 & 2.01 & 2.82 & 5.92 & 8.37 \\
Scaled WY RMSE & 6.29 & 4.36 & 6.08 & 1.96 & 2.81 & 7.55 & 13.24 \\
Scaled RS RMSE & 7.58 & 6.25 & 6.37 & 3.07 & 4.32 & 9.05 & 12.79 \\
Scaled total RMSE & 7.50 & 5.95 & 5.57 & 3.45 & 4.30 & 9.03 & 12.88 \\
RMSE-scaled OF & 7.03 & 5.95 & 4.48 & 3.40 & 4.40 & 8.48 & 12.23 \\
\hline \hline
\end{tabular}

This table reports the mean, median, standard deviation, and 10th, 25th, 75th, and 90th percentiles of several measures of model fit. All statistics weight groups by their size to recover the underlying cross-sectional distributions at the household level. WY (RS) RMSE is the root mean squared error of the $8 \mathrm{WY}$ (RS) moments used in estimation, multiplied by 100 so that the units are percentage points of income or wealth. Scaled WY RMSE divides by the cross-sectional mean of WY, 5.07, to express the WY RMSE in proportional percentage units. Scaled RS RMSE divides by the crosssectional mean of RS, 0.65 , to express the RS RMSE in proportional percentage units. RMSE-scaled OF (objective function) is the square root of the objective function divided by 4 and multiplied by 100 to express it in RMSE-equivalent percentage units. It differs slightly from the average of scaled WY and scaled RS RMSE because of interpolation in our estimation procedure. The cross-sectional means of WY and RS are computed over the 2000-2007 period. There are 4,276 groups containing 298,540 households.

Thus our model has a slightly better mean performance and a much better median performance than a random walk. The standard deviation of the risky share around its group-specific time-series mean has an average across groups of $6.4 \%$ and a median of $5.5 \%$. Thus our model, which captures variation in the risky share with age and wealth accumulation, fits asset allocation better than an atheoretical model that simply captures the mean risky share for each group.

Our estimation procedure takes into account that the wealth-income ratio and the risky share have different units, and scales them in proportion to their grand cross-sectional means. The next two rows of Table 7 similarly divide the RMSEs for the wealth-income ratio and risky share by their grand means of 5.07 and 0.65 , respectively, to express them in proportional units. The mean proportional RMSE is $6.3 \%$ for the wealth-income ratio and $7.6 \%$ for the risky share. 
Finally, we report a transformation of the objective function that is rescaled to express it in RMSE-equivalent units. The objective function is the sum of squared proportional errors, so we divide by the number of auxiliary statistics (16) and take the square root, then multiply by 100 to express the RMSE-scaled objective function in percentage points 18 The bottom row of Table 7 is similar to an average of the previous two rows, with a moderately right-skewed distribution.

Appendix Table A.9 shows how model fit deteriorates under homogenous preferences. The mean RMSE-scaled objective function more than doubles to $16.0 \%$ if we fix RRA at its cross-sectional mean. Fixing TPR at its cross-sectional mean produces a mean RMSE-scaled objective function of $8.6 \%$, and similarly restricting the EIS delivers a mean RMSE-scaled objective function of 7.7\%. Fixing all parameters at their cross-sectional means is disastrous in the sense that it increases the mean RMSE-scaled objective function to $24.8 \%$. A life-cycle model with homogeneous preferences, under our maintained assumption of homogeneous rational beliefs, delivers an extremely poor fit to the cross-section of household behavior.

\subsection{Heterogeneous Beliefs}

We have shown that heterogeneous preferences are essential to fit household behavior if beliefs are homogeneous. It is natural to ask to what extent this finding is driven by our restriction on beliefs. To address this question, in appendix Tables A.10A.12 we consider a simple form of heterogeneity in beliefs by considering three alternative assumptions about the Sharpe ratio: the base value of 0.26 , a high value of 0.40 , and a low value of 0.15 . Then, for each group we pick the Sharpe ratio and

\footnotetext{
${ }^{18}$ Group by group, the result is not exactly the average of the proportional errors for the wealthincome ratio and the risky share because of the interpolation method we use in estimation; and the quantiles of the cross-sectional distribution also may refer to different groups.
} 
preference parameters that minimize the objective function. The base case Sharpe ratio is selected for groups representing $54 \%$ of households, while the low Sharpe ratio and the high Sharpe ratio are each selected for $23 \%$ of households.

Allowing for heterogeneity in household beliefs has only a modest impact on the average preference parameters we estimate. Mean RRA is now 7.80, the mean TPR is $4.72 \%$, and the mean EIS is 1.01 . The cross-sectional standard deviations of the TPR and the EIS are similar to those we estimate in the homogeneous-beliefs case, but the cross-sectional standard deviation of risk aversion is over twice as large at 2.74. The explanation is that the model uses heterogeneous beliefs to better fit wealth accumulation, and offsets belief heterogeneity with RRA heterogeneity to avoid counterfactual heterogeneity in the risky share.

Heterogeneous beliefs necessarily improve the fit of our model by adding free parameters, but the degree of improvement is modest. Appendix Table A.12 shows that the mean RMSE-scaled objective function declines only from 7.03 in the homogeneous-beliefs case to 6.52 in the heterogeneous-beliefs case. Importantly, we also show that the fit of the model is extremely poor when we combine heterogeneous beliefs with homogeneous preferences.

Our results relate to Giglio et al.'s (2021) finding that portfolio choices respond less strongly to investors' self-reported beliefs than a simple Merton model would predict. A possible explanation is that optimistic households tend to also have high risk aversion. Our estimates display this positive correlation between beliefs and risk aversion; however, Appendix Table A.12 shows that a restricted model that imposes homogeneous preferences for groups that share the same beliefs continues to fit very poorly. Overall, these estimates confirm our message that substantial preference heterogeneity is required to fit household financial decisions. 


\section{Conclusion}

In this paper, we have estimated a life-cycle model of consumption-portfolio choice on a panel of Swedish households. Our estimates of the RRA and EIS are only weakly negatively correlated across households, which contradicts the predictions of power utility. The TPR is weakly positively correlated with RRA and negatively correlated with the EIS. We estimate a negative correlation between income volatility and risk aversion. More educated households tend to have higher risk aversion and higher TPR when we control for income volatility. Our results are unlikely to be driven by heterogeneous beliefs about the Sharpe ratio of the aggregate portfolio.

Our results shed light on a number of issues in asset pricing and household finance. In general equilibrium models, Epstein-Zin preferences are popular because they are scale-independent and therefore accommodate economic growth without generating trends in interest rates or risk premia. In particular, the long-run risk literature following Bansal and Yaron (2004) has argued that many asset pricing patterns are explained by a moderately high RRA (typically around 10) and an EIS around 1.5. We estimate a somewhat lower cross-sectional average RRA around 7.5 and a cross-sectional average EIS close to 1. We also estimate a cross-sectionally dispersed EIS such that relatively few households have an EIS between 1 and 2 .

Cross-sectional heterogeneity can break the relation between household preferences and the implied preferences of a representative agent. In a representative-agent economy, preferences with habit formation are needed to generate countercyclical variation in the price of risk (Constantinides 1990, Campbell and Cochrane 1999), but in heterogeneous-agent economies, countercyclical risk premia can arise from time-variation in the distribution of wealth across agents with different but constant 
RRA (Dumas 1989, Guvenen 2009). Gomes and Michaelides (2005 and 2008) illustrate the importance of preference heterogeneity for simultaneously matching the wealth accumulation and portfolio decisions of households. Our empirical evidence can be used to discipline these modeling efforts.

In household finance, there is considerable interest in estimating risk aversion at the individual level and measuring its effects on financial decisions. This has sometimes been attempted using questions in surveys (Barsky, Juster, Kimball, and Shapiro 1997, Vissing-Jørgensen 2003). One difficulty with these attempts is that even if risk aversion is correctly measured, its effects on household decisions will be mismeasured if other preference parameters or the properties of labor income covary with risk aversion. Our estimates suggest that this should indeed be a concern. Similarly, there is interest in measuring the effects of labor income risk on financial risk-taking (Calvet and Sodini 2014, Guiso, Jappelli, and Terlizzese 1996, Heaton and Lucas 2000). Models such as those of Campbell, Cocco, Gomes, and Maenhout (2001) and Cocco, Gomes, and Maenhout (2005) show the partial effect of labor income risk for fixed preference parameters, which will be misleading if risk aversion or other parameters vary with labor income risk. Our estimates suggest that this too is a serious empirical issue.

Our findings may also contribute to an ongoing policy debate over approaches to consumer financial protection. If all households have very similar preference parameters, strict regulation of admissible financial products should do little harm to households that optimize correctly, while protecting less sophisticated households from making financial mistakes. To the extent that households are heterogeneous, however, such a stringent approach can harm some households by eliminating financial products they prefer (Campbell 2016). 


\section{References}

Bach, Laurent, Laurent E. Calvet, and Paolo Sodini, 2020, Rich pickings? Risk, return, and skill in household wealth, American Economic Review 110, 2703-2747.

Bansal, Ravi and Amir Yaron, 2004, Risks for the long run: A potential resolution of asset pricing puzzles, Journal of Finance 59, 1481-1509.

Barsky, Robert, Thomas Juster, Miles Kimball, and Matthew Shapiro, 1997, Preference parameters and behavioral heterogeneity: An experimental approach in the Health and Retirement Study, Quarterly Journal of Economics 112, 537-579.

Betermier, Sebastien, Laurent E. Calvet, and Paolo Sodini, 2017, Who are the value and growth investors? Journal of Finance 72, 5-46.

Bodie, Zvi, Robert C. Merton, and William Samuelson, 1992, Labor supply flexibility and portfolio choice in a life cycle model, Journal of Economic Dynamics and Control 16, 427-49.

Calvet, Laurent E., John Y. Campbell, and Paolo Sodini, 2007, Down or out: Assessing the welfare costs of household investment mistakes, Journal of Political Economy 115, 707-747.

Calvet, Laurent E., John Y. Campbell, and Paolo Sodini, 2009, Fight or flight? Portfolio rebalancing by individual investors, Quarterly Journal of Economics 124, 301-348.

Calvet, Laurent E., Claire Célérier, Paolo Sodini, and Boris Vallée, 2021, Can security design foster household risk-taking?, Journal of Financeforthcoming.

Calvet, Laurent E. and Paolo Sodini, 2014, Twin picks: Disentangling the determinants of risk taking in household portfolios, Journal of Finance 69, 867-906.

Campbell, John Y., 2016, Restoring rational choice: The challenge of consumer financial regulation, Ely Lecture, American Economic Review Papers \& Proceedings $106(5), 1-30$.

Campbell, John Y., Joao Cocco, Francisco Gomes, and Pascal Maenhout, 2001, Investing retirement wealth: A life-cycle model, in John Y. Campbell and Martin Feldstein eds., Risk Aspects of Investment-Based Social Security Reform (University of Chicago Press), 439-473.

Campbell, John Y., and John Cochrane, 1999, By force of habit: A consumption 
based explanation of aggregate stock market behavior, Journal of Political Economy $107,205-251$.

Campbell, John Y. and Luis Viceira, 2002, Strategic Asset Allocation: Portfolio Choice for Long-Term Investors (Oxford University Press).

Carroll, Christopher D., 2002, Portfolios of the rich, in Luigi Guiso, Michael Haliassos and Tullio Jappelli, eds. Household Portfolios (MIT Press).

Carroll, Christopher D., and Andrew Samwick, 1997, The nature of precautionary wealth, Journal of Monetary Economics 40, 41-71.

Castaneda, Ana, Javier Diaz-Gimenez, and Jose-Victor Rios-Rull, 2003, Accounting for the U.S. earnings and wealth inequality, Journal of Political Economy, 111, 818857.

Cocco, Joao, Francisco Gomes, and Pascal Maenhout, 2005, Consumption and portfolio choice over the life cycle, Review of Financial Studies 18, 491-533.

Constantinides, George, 1990, Habit formation: A resolution of the equity premium puzzle, Journal of Political Economy 98, 519-543.

De Nardi, Mariacristina, 2004, Wealth inequality and intergenerational links, Review of Economic Studies, 71, 743-768.

Dumas, Bernard, 1989, Two-person dynamic equilibrium in the capital markets, Review of Financial Studies, 2, 157-188.

Du Rietz, Gunnar, Dan Johansson, and Mikael Stenkula, 2015, Swedish capital income taxation (1862-2013), in Magnus Henrekson and Mikael Stenkula eds. Swedish Taxation: Developments since 1862 (Palgrave Macmillan), 123-178.

Epstein, Larry G. and Stanley E. Zin, 1989, Substitution, risk aversion, and the temporal behavior of consumption and asset returns: A theoretical framework, Econometrica 57, 937-969.

Fagereng, Andreas, Charles Gottlieb, and Luigi Guiso, 2017, Asset market participation and portfolio choice over the life-cycle, Journal of Finance 72, 705-750.

Giglio, Stefano, Matteo Maggiori, Johannes Stroebel, and Stephen Utkus, 2021, Five facts about beliefs and portfolios, American Economic Review 111, 1481-1522

Gomes, Francisco, and Alexander Michaelides, 2005, Optimal life-cycle asset allo- 
cation: Understanding the empirical evidence, Journal of Finance 60, 869-904.

Gomes, Francisco, and Alexander Michaelides, 2008, Asset pricing with limited risk sharing and heterogeneous agents, Review of Financial Studies 21, 415-448.

Gouriéroux, Christian, Alain Monfort, and Eric Renault, 1993, Indirect inference, Journal of Applied Econometrics 8, S85-S118.

Guiso, Luigi, Tullio Jappelli, and Daniele Terlizzese, 1996, Income risk, borrowing constraints and portfolio choice, American Economic Review 86, 158-171.

Guvenen, Fatih, 2009, A parsimonious macroeconomic model for asset pricing, Econometrica 77, 1711-1750.

Heaton, John, and Deborah Lucas, 2000, Portfolio choice and asset prices: The importance of entrepreneurial risk, Journal of Finance 55, 1163-1198.

Kocherlakota, Narayana R., 1990, Disentangling the coefficient of relative risk aversion from the elasticity of intertemporal substitution: An irrelevance result, Journal of Finance 45, 175-190.

Low, Hamish, Costas Meghir, and Luigi Pistaferri, 2010, Wage risk and employment risk over the life cycle, American Economic Review 100, 1432-1467.

Meeuwis, Maarten, Jonathan A. Parker, Antoinette Schoar, and Duncan I. Simester, 2021, Belief disagreement and portfolio choice, Journal of Finance, forthcoming.

Mehra, Rajnish and Edward Prescott, 1985, The equity premium: A puzzle, Journal of Monetary Economics 15, 145-161.

Smith, Anthony, 1993, Estimating nonlinear time series models using simulated vector autoregressions, Journal of Applied Econometrics 8, S63-S84.

Svensson, Lars E.O., 1989, Portfolio choice with non-expected utility in continuous time, Economics Letters 30, 313-317.

Vissing-Jørgensen, Annette, 2003, Perspectives on behavioral finance: Does "irrationality" disappear with wealth? Evidence from expectations and actions, NBER Macroeconomics Annual 18, 139-194.

Wachter, Jessica, and Motohiro Yogo, 2010, Why do household portfolio shares rise in wealth?, Review of Financial Studies 2, 3929-3965. 